\title{
FUZZY - BASED MULTI - CRITERIA DECISION SUPPORT SYSTEM FOR MAINTENANCE MANAGEMENT OF WASTEWATER TREATMENT PLANTS
}

\author{
Reem Tareq AL-ATTAR ${ }^{1, *}$, Mahmoud Saleh AL-KHAFAJI ${ }^{2}$, Faris H. AL-ANI ${ }^{3}$ \\ ${ }^{1}$ University of Technology, Baghdad, Iraq \& Al-Esraa University College, Baghdad, Iraq. \\ ${ }^{2}$ Al-Nahrain University, Baghdad, Iraq. \\ ${ }^{3}$ University of Technology, Baghdad, Iraq. \\ corresponding author: r.t.alattar@gmail.com
}

\section{Abstract}

Wastewater treatment plants (WWTPs) contain a large number of components, and these components in turn require a large number of maintenance activities and high costs. In this paper, a Fuzzy-based Multi-Criteria Decision Support System (FBMCDS) model was designed based on the failure mode and effect analysis FM-EA and applied to the Rustumiya Project (RP) in Iraq. Information of the RP's components, failure modes, applied maintenance activities and costs were collected from the documented data, site visit and face-to-face interviews as well as opinions of 44 experts. Through applying the fuzzy logic to analysis the failure modes and effects, the risk priority index (FMRPI) and total intensity (FMTI) of each failure mode ware computed. Thus, maintenance priorities and weights of the RP's failure modes were specified. In addition, the best maintenance plan was specified based on the FMRPI-FMTI diagram that shows the importance and the type of maintenance required for each failure mode. Failure of the submersible pump has the first rank in terms of priority, while the last priority was occupied by the building failure mode, where the mechanical failure modes are of the highest importance, followed by the electrical failure modes. Finally, the construction failure modes are ranked last due to the small probability of failure. The designed model is considered an efficient tool due to the similarity of the results with the reality of the situation and the ease of reading and displaying the results. In addition, this model can be applied to other projects such as water treatment plants and irrigation projects.
\end{abstract}

Keywords:

FMCDM;

Wastewater treatment plants; Failure mode and effect analysis; Risk priority index;

Total intensity.

\section{Introduction}

The world is facing rapid and huge developments in various aspects of life, which makes the major resources granted by mother earth insufficient and destined to regression. Therefore, we as human beings live and die on earth it is our duty to take care of its resources, knowledge about the quality of water resources is a significant need to preserve and control their consumption [1], it can be simply inferred that most of the water bodies around the world are diminishing. One of the most important solutions to control the quantities of water used and the quality of water returned to water resources is the wastewater treatment plants (WWTPs). Ordinarily, WWTPs get rid of large quantities of suspended and dissolved solids, in addition to a high percentage of organic matter through a series of activities (physical, chemical, and biological) that end with an acceptable water quality within the rules and regulations that differs in every region in the world. Therefore, a large proportion of consumed water returns to its original water body with an acceptable water quality.

Year after year, the significance of maintenance management is increasing. The process of developing projects to the modern state and adopting machines and automation instead of manpower 
led to an increase in costs in general, and particular maintenance costs. One of the most important reasons for maintenance management is to determine whether the plant's budget is sufficient to cover the maintenance budget and therefore sufficient to cover all important maintenance activities. Finally, ensuring the effectiveness of all parts of the station. As a result, guarantee operational capacity that is suitable for the type of load entering the WWTP.

In Iraq, most of the WWTPs are in poor condition and desperate need of comprehensive maintenance operations and organizational activities, due to the economic crises that the country faces. Therefore, the financial budget of maintenance is not enough to cover all the maintenance activities. Therefore, it is necessary to propose appropriate plans in spending the maintenance budget in the plant to enhance its efficiency and maintain it for the longest possible time.

On the other hand, it is known that the economic crisis has wide effects on various fields around the world, and one of these aspects is the lack of adequate financial budgeting for the maintenance of WWTPs, which makes them operate with less efficiency than required or less than design efficiency. WWTPs and their components usually undergo different types of failures that vary in type, periods of occurrence, consequences, risks, and costs according to the type of component, its origins, and design. These types of failures can be divided in general into three main categories, which are mechanical, electrical, and construction failures. Therefore, developing a system for prioritizing maintenance activities according to importance ensures the continuation of the plants' work with the highest possible efficiency within financial limits.

The development of such systems can be done by utilizing many different methods but the multi-criteria decision making (MCDM) is the go-to approach in dealing with multi-solution problems or decisions of multiple criteria with varying effects, which is the type of problems faced in the real world, where direct numbers and equations are unable to provide direct solutions [2]. Form another point of view, MCDM is one of the many found evaluation research methods, which is used as a means for facilitating solving assessment and selection problems associated with multiple criteria that have different effects [3].

Recently, MCDM is used in combination with other techniques to obtain easier analysis methods and clearer results. Such as, the analytical hierarchy process (AHP), Technique for Order Preference by Similarity to Ideal Solution (TOPSIS), Grey Relational Analysis (GRA), the fuzzy logic $(\mathrm{FL})$, and others [3]. The application of these techniques took place in numerous research papers. In 2003, [4] use this technique for the supplier selection problem. Whereas, [5] recommended the use of the AHP process when involved in multi-criteria, sub-criteria, and other types of complicated decisionmaking problems. Another technique for the evaluation is the TOPSIS, which is applied for suppliers selection problem by [6], While it has been used by [7] as a tool for decision-making process. For the GRA method, it was used to analyze the external environmental factors on oil pipelines [8]. Then, [9] combined the GRA with grey decision making as an assessment method. Finally, the FL which might not be the only tool to deal with ambiguous data but it's one of the most important. This is due to its flexibility in data controlling, no need for a professional user because of its easy interpretation, it considered the natural form for processing ambiguous data, and learning and interpretation it is done easily [10]. This method has been adopted in various fields and is in continuous development until the present time. Such as in manufacturing [11] suggested the FL as a means to include the uncertainty and impressions in the faced issues in manufacturing by proposing an algorithm to facilitate the use and understanding of the fuzzy logic in manufacturing, in the same year, [12] utilized the FL as a control algorithm that used to solve a particular control issue without the need for special tools. Recently, [13] made use of the FL in line with the MCDM as a tool for prioritizing and weighing maintenance activities in irrigation projects.

The failure mode and effect analysis (FM-EA) is a tool developed to identify, evaluate and reduce future risks to a product or process, the fuzzy-based FM-EA model has many features, which includes that this model permits utilizing relationships that are nonlinear between the RPI and its major three criteria. It is powerful in dealing with vagueness and uncertainty. Finally, it facilitates the use of qualitative data, instead of quantitative [14]. Here the F-FM-EA is used as a tool for prioritizing maintenance activities by utilizing the Risk Priority Index (RPI) and the Total Intensity (TI). The FM-EA is known for being an uncomplicated tool that decreases future failure repetition and by that reducing the cost of maintenance in projects, minimizing the odds of dramatic issues, and can be considered as recorded data for future problems [15]. The RPI is computed by multiplying the three main criteria (Occurrence, Detection, and Consequences), which is evaluated by an expert through the use of a questionnaire using a scale of suitable points' number [16]. However, the $\mathrm{Tl}$ for each failure mode is computed by considering seven indicators (Age, Usage-related risk, Utilization, Number of available 
identical components, Recalls and hazard alerts, Function, and Maintenance requirements), which are also evaluated by experts through the use of a questionnaire [17]. The combination of these methods gives a simple technique in evaluating the failure modes by computing the Failure Mode Risk Priority index (FMRP) and Failure Mode Total Intensity (FMTI) that end by prioritizing these failure modes according to their importance and the risk of their impact on the operation of the considered project.

Due to lack in the previous research studies related to the management of maintenance plans in WWTPs worldwide. Moreover, the WWTPs in Iraq are mostly damaged and outdated which make it in desperate need for a comprehensive maintenance plan. This highlights the importance of considering this issue. Thus, this paper aims at developing a MCDM model to manage the maintenance activities based on computing the priorities and weights of the failure modes for all components of the considered WWTP, as well as determining the best maintenance plan, including the importance and type of maintenance required for each component and failure mode in the WWTP.

\section{Materials and methods}

The cornerstone of a successful decision-making system is the collection of sufficient data at a standard level. In this paper, data was collected from three directions as shown in Fig. 1 starting with the previously recorded data of failures, the type and intensity of maintenance for each failure, followed by successive visits to the study area to interview those responsible for maintenance and operation within WWTP and discuss the maintenance plan, and finally sending the designed questionnaire to a group of experts who were selected according to their specializations, experiences, and place of work. The formation of the maintenance budgeting plan starts from the examination of the different parts of the WWTP's components in general and for the chosen sample which represents the case study. This examination includes breaking apart component to the last screw to recognize it and find its weakest points using the maintenance manual as a guide for parts which requires special or critical maintenance activities. The next step is the field visit of the chosen case study for this paper, which is the Rustumiya Project (RP) WWTP for achieving face-to-face interviews with the staff members in charge of maintenance and operation of the WWTP's components. From these interviews, different experiences and opinions were obtained and analyzed. This is followed by acquiring all possible information and manuals related to the maintenance and operation of the RP WWTP. In this paper, the fuzzy decision support system is presented as a tool for MCDM and this is due to the flexibility of the FL, its easy interpretation cancels the need for expertise in dealing with it. Further, it is considered the natural form for processing ambiguous data [10]. The FL is used to design the FuzzyBased Multi-Criteria Decision Support System (FBMCDS) model based on RPI and TI. The FMRPI depends on the rating of Detection $D e$, Occurrence $O c$ and Consequences $C o$ as main indicators, where each has own sub-indicators, of the Failure modes. However, FMTI is computed based on the rating of Age, URR, Utilization, Number of identical components, Alerts and recalls hazards, Function, and Maintenance requirements indicators of the project components. These ratings were obtained through applying the FL on the collected data of the RP WWTP, form document, site visit and a questionnaire of experts' opinion, concerns specifying the failure modes and the linguistic evaluation of the main and sub indicators.

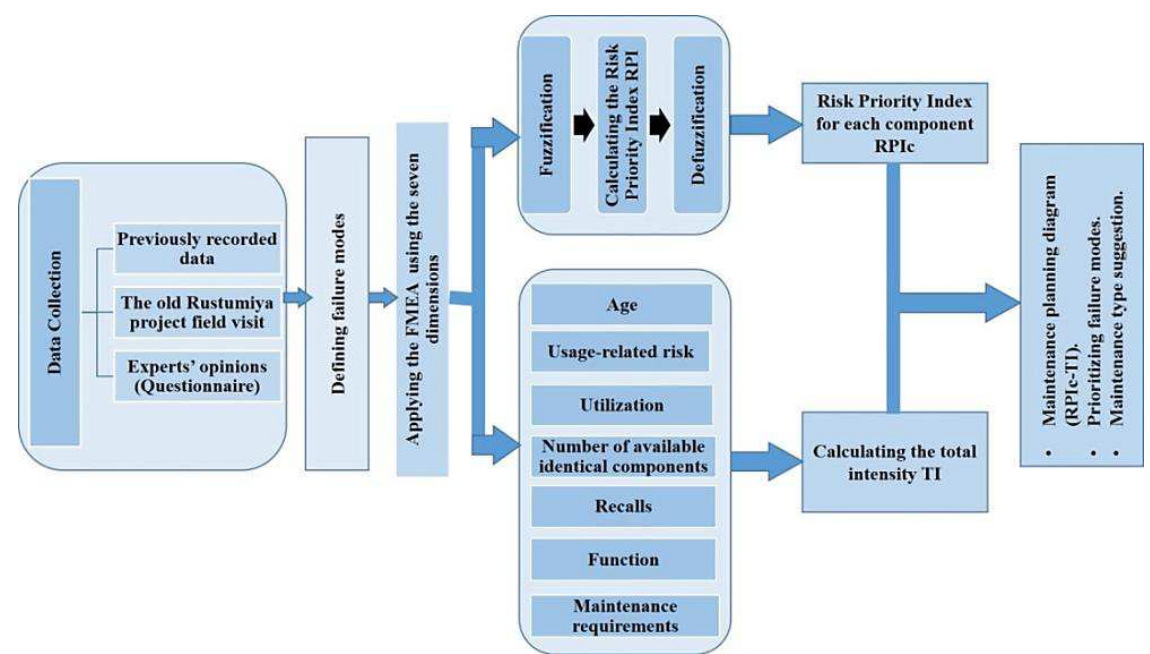

Fig. 1: Schematic diagram of the methodology. 


\subsection{Study area}

The Old Rustumiya WWTP, Fig. 2 is located on the banks of the Diyala River, south of Baghdad, in the Rustumiya area at the end of the main Baghdad sewage line. It serves the areas of Baghdad located between the Army Canal in the east and the Tigris River in the west, starting from the Adhamiya area in the north to the Al Rustumiya area in the south which serves about two million people.

The basic stage, which is called the zero stage, was established in 1963 with a design capacity of $40,000 \mathrm{~m}^{3} /$ day, in 1974 the first expansion (1 stage) was partially integrated with the basic stage with a design capacity of $45,000 \mathrm{~m}^{3} /$ day. Finally, the second expansion (stage 2) was added in 1981 with a design capacity of $90000 \mathrm{~m}^{3} /$ day thus the total project capacity became $175,000 \mathrm{~m}^{3} /$ day containing the components shown in Table 1, this project extends over a land area of $1000 \times 700 \mathrm{~m}^{2}$.

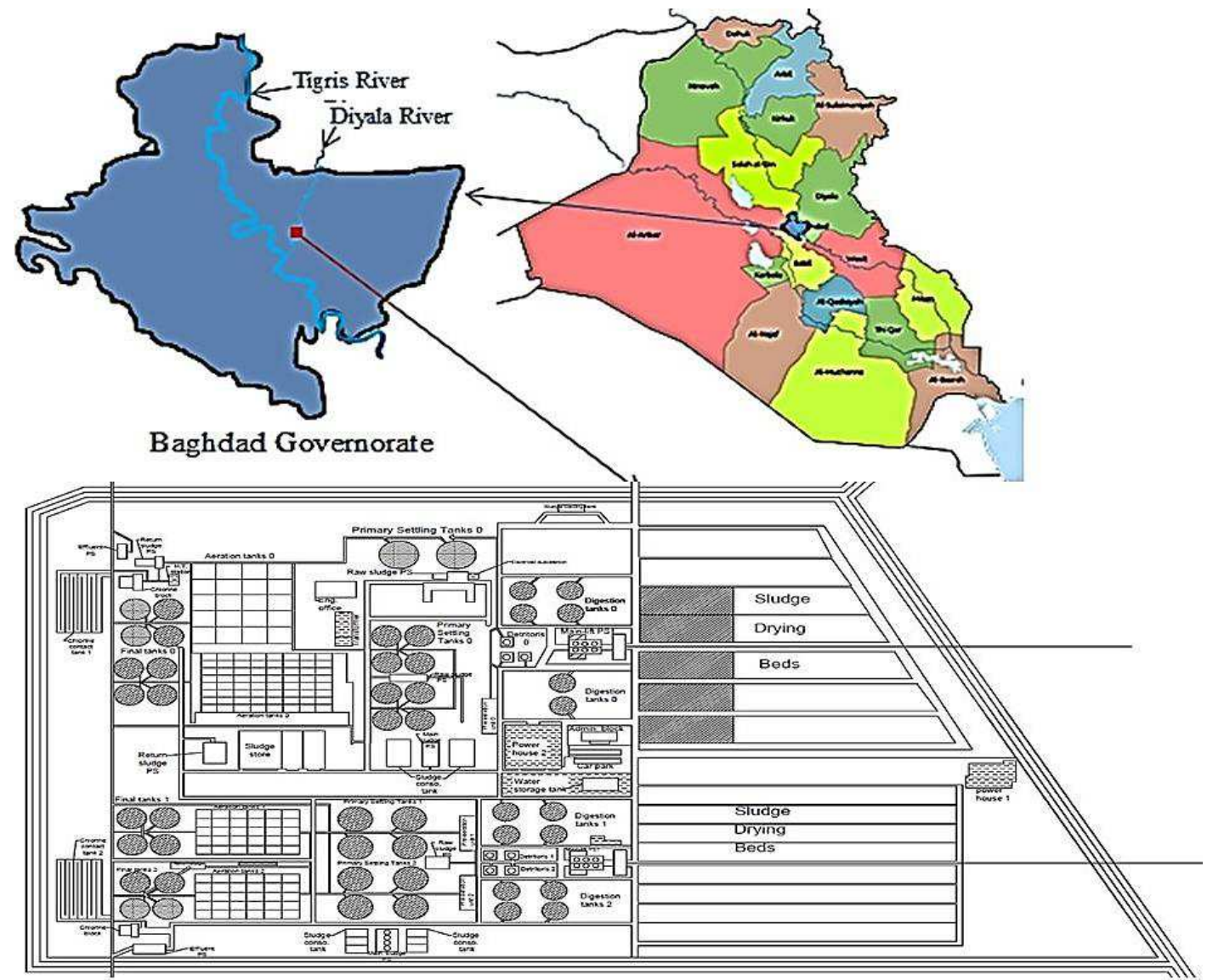

Fig. 2: Location and layout of the Rustumiya WWTP.

Table 1: The Old Rustumiya Project's components, Line 0, Line 1 and 2.

\begin{tabular}{|c|c|c|c|}
\hline \multirow{2}{*}{ Sequence } & Component & \multicolumn{2}{|c|}{ Number } \\
\cline { 3 - 4 } & & Line 0 & Line 1 \& 2 \\
\hline 1 & Screens building & 1 & 1 \\
\hline 2 & Main lift pumping station & 1 & 1 \\
\hline 3 & Detritions & 3 & 4 \\
\hline 4 & Pre-aeration tank & 1 & 2 \\
\hline 5 & Primary settling tanks & 10 & 8 \\
\hline 6 & Aeration tanks & $20+80$ & 60 \\
\hline 7 & Final settling tanks & 8 & 8 \\
\hline 8 & Chlorine contact tank & 1 & 1 \\
\hline 9 & Final pumping station & 1 & 1 \\
\hline
\end{tabular}




\begin{tabular}{|c|c|c|c|}
\hline \multicolumn{4}{|c|}{ Sludge treatment units } \\
\hline \multirow{2}{*}{ Sequence } & Component & \multicolumn{2}{|c|}{ Number } \\
\cline { 3 - 4 } & & Line 0 & Line 1 \& 2 \\
\hline 1 & Raw sludge pumps & 2 & 1 \\
\hline 2 & Return sludge pumping station & 2 & 1 \\
\hline 3 & Main sludge pumping station & 1 & 1 \\
\hline 4 & Consolidation tanks & 2 & 2 \\
\hline 5 & Sludge drying beds & 7 & 8 \\
\hline
\end{tabular}

\subsection{Fuzzy logic}

Fuzzy logic is the accurate logic of the inaccurate data that can also be understood as interpretation means for some human abilities like that ability of reasoning and making rational decisions in an imprecise environment other than the ability to complete a various range of activities mentally and physically in the absence of clear planning and computations [18]. The fuzzy logic is based upon the fuzzy set theory which is a generalization of the original set theory, works based on defining a state or a condition that is neither true nor false thus providing flexibility to sense inaccuracy and uncertainty, Fig. 3 (based on [19]).

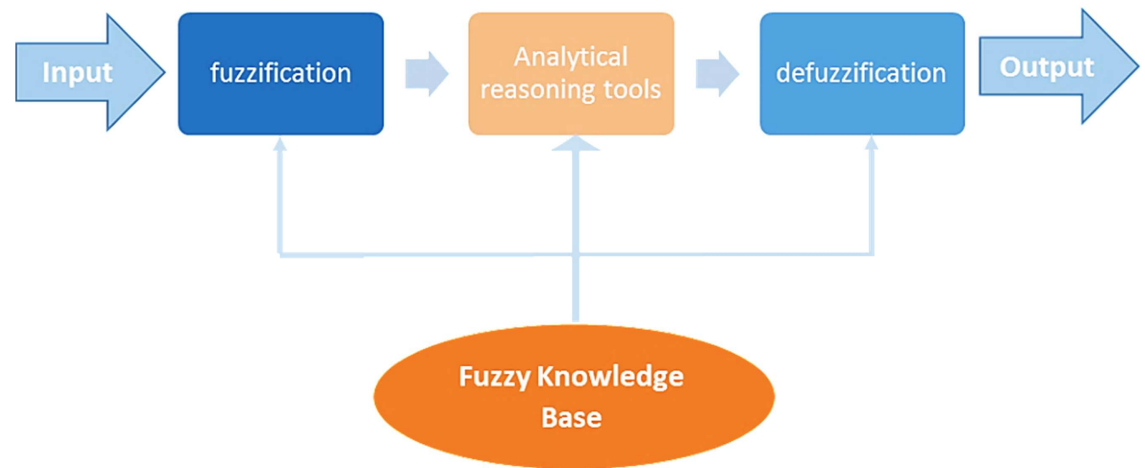

Fig. 3: Overview diagram of a fuzzy system (based on [19]).

\subsection{Failure mode and effect analysis (FM-EA)}

FM-EA is a designed methodology, see Fig. 4, to facilitate the process of recognizing failure modes and study their future effects on the system and its user for a certain project, it is also used for prioritizing feature to arrange failure modes according to their importance. In addition, finding the best solution for serious problems and how to avoid them [20].

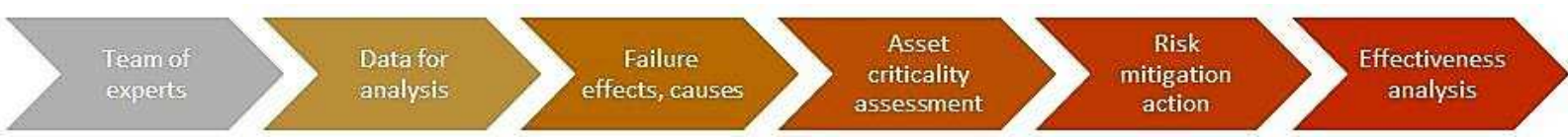

Fig. 4: Diagram of the FM-EA process.

The methodology of preparing and implementation of the Fuzzy Failure Mode and Effect Analysis model (F-FM-EA) was for applying F-FM-EA: the Detectability De, Occurrence Oc, and Consequences $\mathrm{Co}$ indicators of failure modes are to be considered for each component in the WWTP in order to determine the Risk Priority Index for each failure modes (FMRPI).

- Detectability $\boldsymbol{D e}$ which state the capability to detect failure, contains two sub-indicators the non-detection probability $D e 1$ and failure detection method De2 The non-detection probability De1 is a sub-indicator that describes the likelihood of non-detection cases. Nevertheless, these cases depend majorly on the staff of maintenance and their skills and abilities in detecting failures. There are four points to be examined when evaluating this sub-indicator (visibility, detection through automatic devices, detection after inspection, and detection during inspection). Table 2 shows the rating of nondetection probability and the corresponding fuzzy numbers. Failure detection methods De2 is another sub-indicator of the detection failure mode that describes the automation of the inspection process, the description and corresponding fuzzy numbers showed in Table 3. 
Table 2: Ratings for detection assessment of a failure De1 [22].

\begin{tabular}{|c|c|c|c|c|c|c|c|c|c|c|c|}
\hline Rating & & Visibility & & $\begin{array}{r}\text { Detecti } \\
\text { dia }\end{array}$ & $\begin{array}{l}\text { via auton } \\
\text { nostic aids }\end{array}$ & & $\begin{array}{r}\text { Dete } \\
\text { a } \\
\text { insp }\end{array}$ & $\begin{array}{l}\text { tion } \\
\text { tion } \\
\text { tion }\end{array}$ & $\begin{array}{l}\text { Sche } \\
\text { insp }\end{array}$ & $\begin{array}{l}\text { uled } \\
\text { tion }\end{array}$ & $\begin{array}{c}\text { Fuzzy } \\
\text { number }\end{array}$ \\
\hline Probability of detection & Yes & Partially & No & Directly & Indirectly & No & Yes & No & Yes & No & \\
\hline Almost certain $(\mathrm{AC})$ & $\sqrt{ }$ & & & & & & & & & & $1,1,2$ \\
\hline Very high (VH) & & $\sqrt{ }$ & & $\sqrt{ }$ & & & $\sqrt{ }$ & & & & $1,2,3$ \\
\hline High $(\mathrm{H})$ & & & $\sqrt{ }$ & & $\sqrt{ }$ & & $\sqrt{ }$ & & $\sqrt{ }$ & & $2,3,4$ \\
\hline Moderately high $(\mathrm{MH})$ & & & $\sqrt{ }$ & & $\sqrt{ }$ & & $\sqrt{ }$ & & & $\sqrt{ }$ & $3,4,5$ \\
\hline Moderate (M) & & $\sqrt{ }$ & $\sqrt{ }$ & & $\sqrt{ }$ & & & $\sqrt{ }$ & $\sqrt{ }$ & & $4,5,6$ \\
\hline Low (L) & & & & & $\sqrt{ }$ & & & $\sqrt{ }$ & & $\sqrt{ }$ & $5,6,7$ \\
\hline Very low (VL) & & & $\sqrt{ }$ & & & $\sqrt{ }$ & $\sqrt{ }$ & & $\sqrt{ }$ & & $6,7,8$ \\
\hline Remote $(\mathrm{R})$ & & & $\sqrt{ }$ & & & $\sqrt{ }$ & $\sqrt{ }$ & & & $\sqrt{ }$ & $7,8,9$ \\
\hline Very remote $(\mathrm{VR})$ & & & $\sqrt{ }$ & & & $\sqrt{ }$ & & $\sqrt{ }$ & $\sqrt{ }$ & & $8,9,10$ \\
\hline Absolute uncertainty (AU) & & & $\sqrt{ }$ & & & $\sqrt{ }$ & & $\sqrt{ }$ & & $\sqrt{ }$ & $9,10,10$ \\
\hline
\end{tabular}

Table 3: Ratings for systematic method of failure detection De2 [22].

\begin{tabular}{|c|c|c|}
\hline Rating & Description & Fuzzy numbers \\
\hline Remote/unreliable (R) & $\begin{array}{l}\text { The device is } 100 \% \text { inspected and the inspection process is automatic, } \\
\text { for example, automatic sensors have been installed in the device }\end{array}$ & $0,0,1.5$ \\
\hline Low (L) & There is a complete inspection, but it is not automated. & $1,2.5,4$ \\
\hline Moderate (M) & $\begin{array}{c}\text { There is a process for manual inspection and it is applied only } \\
\text { to some components in the device. }\end{array}$ & $3.5,5,6.5$ \\
\hline High $(H)$ & $\begin{array}{l}\text { There is no inspection process for the device and the failure } \\
\text { has been allowed to occur. }\end{array}$ & $6,7.5,9$ \\
\hline Very high $(\mathrm{VH})$ & $\begin{array}{l}\text { There is no known inspection process for detecting the device failures and } \\
\text { the failures can hardly be detected even with a complete inspection. }\end{array}$ & $8.5,10,10$ \\
\hline
\end{tabular}

- Occurrence $\boldsymbol{O c}$ indicator describes the potential repetition of failure in a part of a certain component in the WWTP and it consists of three sub-indicators the Time of failure Oc1, Repeatability Oc2, Visibility Oc3, fuzzy numbers, and rating are illustrated in Table 4. Time of failure Oc1 represents the time period between two failures in the same part of a certain component. Furthermore, the previously recorded data, the experience of maintenance staff, the expert's opinions can be very beneficial for determining the time of failure. Repeatability Oc2 represents the potential number of failures during a specific time period for the same part of a certain component. Visibility Oc3 represents the ability to recognize a failure by considering the reachability of remote and covered parts of components.

Table 4: Elements and ratings of occurrence Oc sub-indicator [22].

\begin{tabular}{|c|c|c|c|c|c|}
\hline \multirow[b]{2}{*}{ Rating } & \multicolumn{2}{|c|}{ Oc1 } & \multirow{2}{*}{$\begin{array}{c}\text { Oc2 } \\
\text { Corresponding time }\end{array}$} & \multirow{2}{*}{$\frac{O c 3}{\text { Corresponding time }}$} & \multirow{2}{*}{$\begin{array}{c}\text { Fuzzy } \\
\text { numbers }\end{array}$} \\
\hline & $\begin{array}{l}\text { Chance } \\
\text { of failures }\end{array}$ & $\begin{array}{l}\text { Corresponding } \\
\text { time of failure }\end{array}$ & & & \\
\hline Very high (VH) & $\begin{array}{c}\text { Failure is almost } \\
\text { inevitable }\end{array}$ & $<3$ months & $\begin{array}{r}\text { Same } \\
3 \mathrm{~m}\end{array}$ & It is not visible at all. & $8.5,10,10$ \\
\hline High $(H)$ & Repeated failures & $3-6$ months & $\begin{array}{r}\text { Same } \\
3-6\end{array}$ & $\begin{array}{r}\text { Visible whil } \\
\text { the dev }\end{array}$ & $6,7.5,9$ \\
\hline Moderate (M) & Occasional failures & 6 months to 2$)$ & $\begin{array}{l}\text { Same failures in } \\
6-24 \text { months }\end{array}$ & $\begin{array}{l}\text { Visible between two } \\
\text { inspection intervals }\end{array}$ & $3.5,5,6.5$ \\
\hline Low (L) & Relatively few failures & $2-1$ & $\begin{array}{l}\text { Same failures in } \\
2-10 \text { years }\end{array}$ & $\begin{array}{l}\text { Visible while } \\
\text { inspecting }\end{array}$ & $1,2.5,4$ \\
\hline Remote (R) & Failure is unlikely & $>10$ years & $\begin{array}{c}\text { Failure is unlikely }>10 \\
\text { years }\end{array}$ & $\begin{array}{l}\text { Visible before an } \\
\text { inspection }\end{array}$ & $0,0,1.5$ \\
\hline
\end{tabular}

- Consequences Co has four major sub-indicators to consider and these are Safety of users Co1, Safety of operation and maintenance staff Co2, Repair time Co3, and Economic losses Co4, thus all aspects should be considered in determining the total consequences for each part, ratings and fuzzy numbers are listed in Table 5. Safety of users Co1 and Safety of operation and maintenance staff Co2 represents the first and second sub-indicator of the consequences failure mode is stated according to the standard safety rules for each WWTP's component within the operation manuals, 
previously recoded data of hazardous cases resulting from failure can be used to facilitate recognizing the effects of each potential failure. Repair time $\mathbf{C o 3}$ is the mean repair time (MTR) is a tool widely used for measuring the maintainability for devices and in our case WWTP's components, its calculated by dividing the total maintenance period by the number of maintenance activities during a specified period of time [17]. Economic losses Co4 is the result of summation of the cost of maintenance Mc (including the direct and indirect costs), the daily losses caused by maintenance delay Md, losses in WWTP function, and the inability of components to achieve their [17]. The following equations sums the calculation of the economic losses for each component:

$M c=C f+D T \times C v$,

where $C f$ is direct cost of failure $f, C v$ is indirect cost of failure $f, D T$ is repair time (day).

$M d=D T \times M d p h$

where $M d p h$ is the daily losses caused by maintenance delay (cost/day).

$\operatorname{Co} 4=\sum_{i=1}^{n}(M d+M c)$,

where $n$ is the number of predicted failure for each component.

Table 5: Sub-indicator of consequences of Failure Co [22] and according to documented data of Rustumiya WWTP Administration (unpublished official documents).

\begin{tabular}{|c|c|c|c|c|}
\hline Level & Co1 and Co2 & Co3 & Co4 & $\begin{array}{c}\text { Fuzzy } \\
\text { number }\end{array}$ \\
\hline Very high (VH) & Death & Order a new device & Economic loss $\geq 500,000,000$ ID & $8.5,10,10$ \\
\hline High (H) & $\begin{array}{c}\text { Debilitating long-term } \\
\text { injury }\end{array}$ & $\begin{array}{c}\text { External intervention } \\
\text { for repairs }\end{array}$ & $\begin{array}{c}100,000,000 \text { ID } \leq \text { economic loss } \\
<500,000,000 \text { ID }\end{array}$ & $6,7.5,9$ \\
\hline Moderate (M) & Moderate injury & 7days $\leq$ MTR $<90$ days & $\begin{array}{c}20,000,000 \text { ID } \leq \text { economic loss } \\
<100,000,000 \text { ID }\end{array}$ & $3.5,5,6.5$ \\
\hline Low (L) & Minor injury or illness & 1 day $\leq$ MTR $<7$ days & $\begin{array}{c}2,000,000 \text { ID } \leq \text { economic loss } \\
<20,000,000 \text { ID }\end{array}$ & $1,2.5,4$ \\
\hline $\begin{array}{c}\text { Remote } \\
(\mathrm{R})\end{array}$ & Less or no effect & MTR<1 day & 0 ID Economic loss <2,000,000ID & $0,0,1.5$ \\
\hline
\end{tabular}

\subsubsection{Fuzzification and defuzzification}

To achieve a crisp risk priority index for all components within the WWTP FMRPI. The previous proposed fuzzy relations are used to fuzzify all the main and sub indicators.subsequently, the fuzzy rating of these indicators should be defuzzified. The more critical the failure the higher FMRPI it has [17].

Presenting $O c^{n}{ }_{j k l}, C o^{n}{ }_{j k l}, D e^{n}{ }_{j k l}$, where $O c$ is occurrence, $C o$ is consequence, $D e$ is detection, $J$ is component number, $k$ is failure type, $l$ is evaluated sub-indicator, $n$ is expert number. Defining the fuzzy membership function as:

$O c^{n}{ }_{j k l}=\left(L O c^{n}{ }_{j k l}, M O c^{n}{ }_{j k l} \cup O c^{n}{ }_{j k l}\right)$, where $0 \leq L O c^{n}{ }_{j k 1} \leq M O c^{n}{ }_{j k l} \leq U O c^{n}{ }_{j k l} \leq 10$,

$\operatorname{Co}^{n}{ }_{j k l}=\left(L C o^{n}{ }_{j k l}, M C o^{n}{ }_{j k l}, U C o^{n}{ }_{j k l}\right)$, where $0 \leq L C o^{n}{ }_{j k l} \leq M C o^{n}{ }_{j k l} \leq U C o^{n}{ }_{j k l} \leq 10$,

$D e^{n}{ }_{j k l}=\left(L D e^{n}{ }_{j k l}, M D e^{n}{ }_{j k l}, U D e^{n}{ }_{j k l}\right)$, where $0 \leq L D e^{n}{ }_{j k l} \leq M D e^{n}{ }_{j k l} \leq U D e^{n}{ }_{j k l} \leq 10$.

This is followed by adding an experts' weight $W_{i}$, which is calculated from the experience and knowledge of each expert $i$, where these weights range from 0 to 1 , with a total sum equal to 1 . The weight $(\mathrm{W})$ of influence for each the main indicators, weight of $O_{c}\left(W_{O c}\right)$, weight of $C_{O}\left(W_{C o}\right)$ and weight of $D e\left(W_{D e}\right)$ is computed as follows:

$O c_{j k l}=\sum_{i=1}^{n} O c_{i j k l} W_{i}$,

$C o_{j k l}=\sum_{i=1}^{n} \quad C o_{i j k l} W_{i}$,

$D e_{j k l}=\sum_{i=1}^{n} \quad D e_{i j k l} W_{i}$. 
The fuzzy membership function is obtained as:

$\mu(F M R P I)=W_{O c} \mu\left(O c_{j k l}\right)+W_{C o} \mu\left(C o_{j k l}\right)+W_{D e} \mu\left(D e_{j k}\right)$,

where the $\mu(F M R P I)$ should be defuzzified to estimate the crisp FMRPI by using the method of COA (center of area) for its simplicity, the defuzzification (DF) process is explained below:

$$
\begin{aligned}
& D F_{O c}=\frac{1}{3}\left[\left(U_{O c}-L_{O c}\right)+\left(M_{O c}-L_{O c}\right)\right]+L_{O c}, \\
& D F_{C o}=\frac{1}{3}\left[\left(U_{C o}-L_{C o}\right)+\left(M_{C o}-L_{C o}\right)\right]+L_{C o}, \\
& D F_{D e}=\frac{1}{3}\left[\left(U_{D e}-L_{D e}\right)+\left(M_{D e}-L_{D e}\right)\right]+L_{D e}, \\
& F M R P I=D F_{O c} \times D F_{C o} \times D F_{D e},
\end{aligned}
$$

where $L$ is lower value, $M$ is middle value, $U$ is upper value for $(O c, C o$, and $D e)$.

\subsubsection{Failure modes total intensity FMTI:}

There are seven major indicators that effects components prioritizing which is rated from $0 \%$ to $100 \%$ based on experts' opinions and previously recorded data, each part of component within the WWTP is rated with an intensity (Id) that ultimately leads to the failure modes total intensity (FMTI) taking into account the weights of indicators and experts. The following points represent the relevant indicators:

- Age: Reliability of components within the WWTP can be considered as a function of the component's age. Therefore, it is calculated as the number of failures during a specific period of time. Table 6, illustrate the predicted life span for each component based on the condition of components and experts' opinions and experience.

Table 6: Intensity of the expected life of each component of the WWTP.

\begin{tabular}{|c|c|c|}
\hline Age & Description & Intensity [\%] \\
\hline Age $<1$ year & Construction stage & $0-10$ \\
\hline 1 year $<10$ years & Useful life & $10-80$ \\
\hline Age $\geq 10$ years & Wear out stage & $80-100$ \\
\hline
\end{tabular}

- Usage-related risk (URR): The way in which the component is used defines its overall efficiency. Therefore, the frequency of failures due to misuse may outweigh the failure of the component itself. So, the usage-related risk is an important indicator to examine, evaluate, and prioritize by experts in line with guide manuals for each component to recognize the usage-related risks. The linguistic levels and their descriptions are shown in Table 7.

Table 7: Linguistic level with descriptions and intensities for evaluating the usage-related risks (URR) in the WWTP.

\begin{tabular}{|c|c|c|}
\hline Level & Description & Intensity [\%] \\
\hline Very high & Death & 100 \\
\hline High & Long-term injury & $70-90$ \\
\hline Moderate & Moderate injury & $40-70$ \\
\hline Low & Minor injury & $10-40$ \\
\hline Remote & Less or no effect & $<10$ \\
\hline
\end{tabular}

- Utilization (U): By looking at the type of component, operating type, and the number of this type inside the WWTP, it can be concluded that the utilization rate varies. As a result, it is measured based on the weighted summation of the mean daily utilization rate of the component and the ratio between the daily service rate and the maximum service rate. Table 8 , shows the intensity of each utilization level. 
Table 8: Utilization levels and their associated intensity in the WWTP.

\begin{tabular}{|c|c|}
\hline Daily utilization rate of device I (U) & Intensity [\%] \\
\hline $0 \leq U<0.4$ & $0-40$ \\
\hline $0.4 \leq U<0.7$ & $40-70$ \\
\hline $0.7 \leq U$ & $70-100$ \\
\hline
\end{tabular}

- Available identical components: [23] explained that more than one identical component doesn't guarantee its availability. In reality, the rate of daily service of these components is the main feature impacting their availability.the availability is conducted as a function of the number of similar components and their usage per time unit. As [17] suggested, the overall equipment effectiveness $(\mathrm{OEE})$ index to determine the availability of the same components is:

$O E E=$ Availability $\times$ Preformance $\times$ Quality.

The availability is the predicted ratio of the time period that the component is in working state to the number of identical components ( $\mathrm{n}$ )

Availability $=1-\frac{\sum_{n}^{i=1} D t}{n \times 24}$,

where $D t$ : is summation of down time, $n$ components in $t$ time interval.

Preformance $=\frac{A c \times I c}{A o}$,

where $A c$ is the average area covered by $n$ components, $I c$ is standard time of cycle per area, $A o$ is the mean working time of $n$ components. The intensities value is determined after the OEE is computed as shown in Table 9.

Table 9: OEE values and associated intensity in the WWTP.

\begin{tabular}{|c|c|}
\hline OEE & Intensity [\%] \\
\hline $0 \leq$ OEE $<0.5$ & $70-100$ \\
\hline $0.5 \leq$ OEE $<0.7$ & $20-70$ \\
\hline $0.7 \leq$ OEE & $10-20$ \\
\hline
\end{tabular}

- Alerts of recalls and hazards: It is considered a significant indicator in rating components for replacement, and can be used as a function to indicate the number and levels of recalls for each component. According to [17] there are three classes, as listed in Table 10:

- Class 1 recall: there is convenient predicted health risk or death.

- Class 2 recall: temporary or harmful consequences caused by the exposure of violated materials.

- Class 3 recall: there are no convenient predicted consequences.

Table 10: Intensity values of recalls (Alerts of Recalls and Risks) in the WWTP.

\begin{tabular}{|c|c|}
\hline Recalls classes and numbers & Intensity [\%] \\
\hline Total number of Class 1 recalls (per year) $\geq 1$ & 100 \\
\hline $3 \leq$ total number of Class 2 and 3 recalls (per year) $<5$ & $20-60$ \\
\hline $1 \leq$ total number of Class 2 and 3 recalls (per year) $<3$ & $10-20$ \\
\hline
\end{tabular}

- Function: Every WWTP consist of components that vary in usage like main pumping stations, treatment tanks, and sludge processing tanks. Considering the function of each component, and its efficiency the following intensities suggested Table 11. 
Table 11: Component function intensities.

\begin{tabular}{|c|c|}
\hline Class & Intensity [\%] \\
\hline Main lift pumping station PS1 & 12 \\
\hline Screens 1 & 7 \\
\hline Pre-aeration tanks 1 10 \\
\hline Primary settling tanks 0 & 7 \\
\hline Raw sludge pumps 0 & 8 \\
\hline Aeration tanks 0 & 10 \\
\hline Return sludge pumping station 0 & 10 \\
\hline Sludge main pumping station & 8 \\
\hline Chlorine injection system 1 & 7 \\
\hline Consolidation tanks 1 & 6 \\
\hline Effluent pumping station PS1 & 5 \\
\hline Potable water pumping station & 10 \\
\hline
\end{tabular}

- Maintenance requirements: Each component in the WWTP has different requirements for maintenance. [24] proposed that the maintenance activity for each component consists of three types of maintenance requirements: maintenance tools, maintenance materials, and maintenance skills. In Table 12, the total intensity of the maintenance requirements (FMTI) is obtained as the product of the maintenance tools, materials, and skills, and they're not to match other indicator of intensity because they're not probabilistic. Next, the intensity of the maintenance requirements is normalized by dividing the total maintenance requirement intensity (assigned by each expert) by the summation of all intensities specified by other experts for each component.

Table 12: Evaluation of maintenance resources and suggested scores.

\begin{tabular}{|c|c|c|}
\hline Resource & Requirements & Score \\
\hline \multirow{3}{*}{ Maintenance tools } & General tools (multiple alternatives) & 1 \\
\cline { 2 - 3 } & General tools (no alternatives) & 2 \\
\cline { 2 - 3 } & Special tools & 3 \\
\hline \multirow{2}{*}{ Maintenance materials } & No special requirements & 1 \\
\cline { 2 - 3 } & Special requirements & 2 \\
\hline \multirow{3}{*}{ Maintenance skills } & No special requirements & 1 \\
\cline { 2 - 3 } & Level requirements & 2 \\
\cline { 2 - 3 } & High requirements & 3 \\
\hline
\end{tabular}

\subsubsection{FMTI calculations}

Each component within the WWTP is evaluated by $n$ number of experts to every one of the seven indicator, the value of intensity for each indicator is calculated by Eq. (18).

$I d=\sum_{i=1}^{n} W i \times I d i$

where $i$ is the expert number, $W i$ is the experts' weight.

Then the total intensity is calculated by using the weighted sum an analytical hierarchy process (AHP) method has been adopted to obtain the set of weights $W d$ representing the relative importance of each indicator. Weights must be in the $[0,1]$ interval and the sum of weights for all indicators should be equal to 1. Applying this process led to the weights given in Table 13. Finally, Eq. (19) is used for calculating FMTI for each component.

$F M T I=\sum_{j-1}^{d} W d \times I d$. 
Table 13: Weight of relevant indicators.

\begin{tabular}{|c|c|}
\hline Feature & Weight [\%] \\
\hline Age & 14 \\
\hline Usage-related risk & 15 \\
\hline Utilization & 15 \\
\hline Number of available identical components & 15 \\
\hline Recalls & 15 \\
\hline Function & 11 \\
\hline Maintenance requirements & 15 \\
\hline
\end{tabular}

After calculating the intensities of all WWTP components, the next and final step is to prioritize components according to their FMRPI and FMTI. So, a diagram, Fig. 5, is proposed to manage the maintenance plan for each component. This diagram is based on FMRPI and FMTI scores, which are conducted from points $\mathrm{b}$ and $\mathrm{c}$ of our approach.

To prioritize failure modes, the position of each component is plotted on the FMRPI-FMTI Risk diagram (by using FMRPI and FMTI values of this component). The points (coordinates) placed on the diagram display all components and their locations on the diagram represent information regarding the criticality of each component and its maintenance requirements. Fig. 5 shows four zones divided according to [25]:

- The first zone comprises a low priority area where both FMTI and FMRPI have low values and the maintenance type is (corrective maintenance).

- The second zone reveals the second lowest priority zone, including high FMTI scores and low FMRPI values and the maintenance type is (time-based preventive maintenance).

- The third zone is a 'high priority area including high FMRPI and low FMTI scores and the maintenance type is (condition-based maintenance)

- The fourth zone is an 'urgent' area. Components within this zone have very high FMRPI and FMTI values, and therefore they are critical and need to be with a high priority rate and the maintenance type is (preventive maintenance).

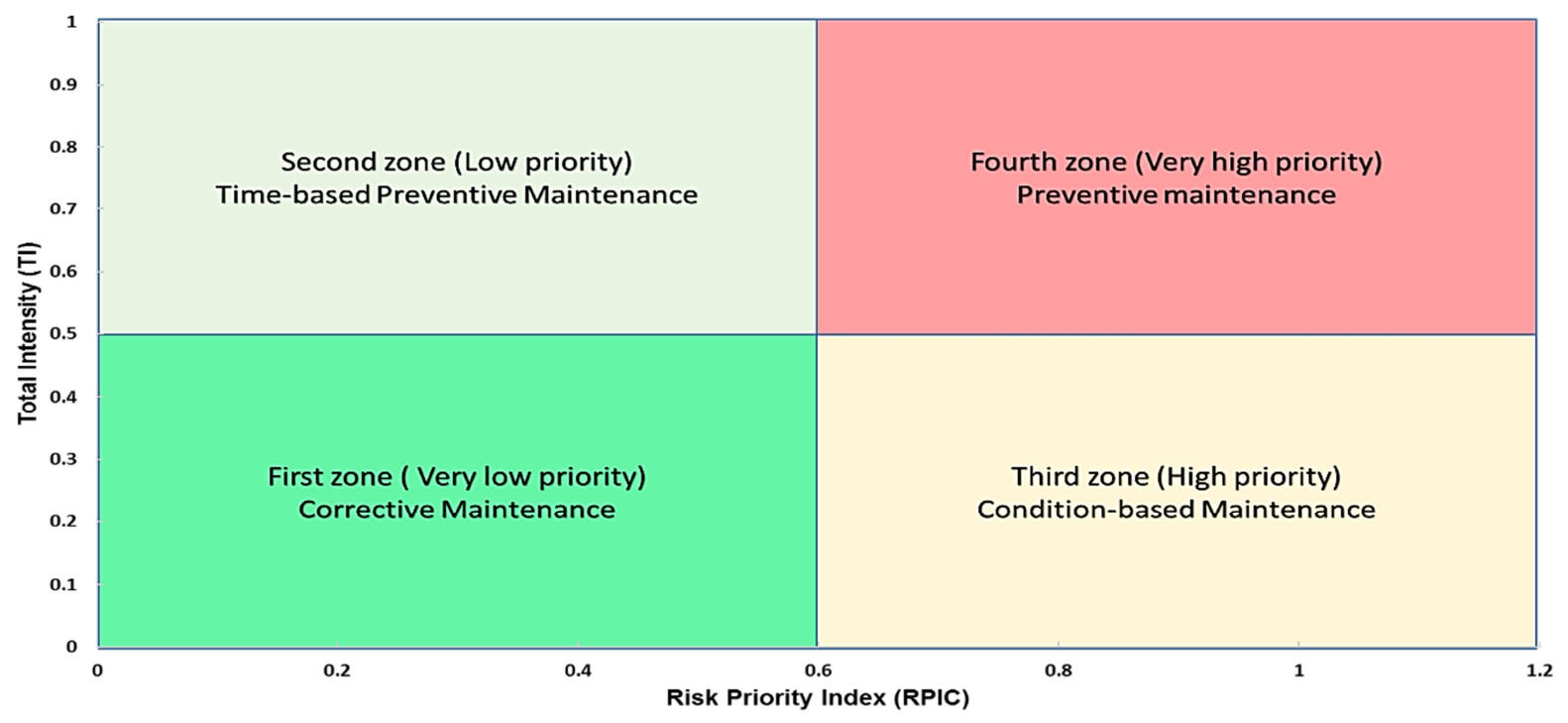

Fig. 5: Maintenance planning diagram (FMRPI-FMTI diagram).

\subsection{Questionnaire design and implementation}

A questionnaire was designed and arranged according to the necessary elements of computing the FMRPI and FMTI, after the complete specification of failure modes for the RP WWTP. Questionnaire questions were focused on the elements involved in evaluation the rates of the main indicators (Detectability $\mathrm{De}$, Occurrence $\mathrm{Oc}$, and Consequences $\mathrm{Co}$ ) and the sub indicators of the specified failure modes of RP WWTP. Inquires about these issues were based on the requirements of fuzzy logic via assessment of standardized linguistic variables with standard ratios of each indicator. 


\section{Results and discussions}

The Fuzzy-based Multi-Criteria Decision Support System FBMCDS model was designed to include the F-FM-EA which is computed through calculating the FMRPI and FMTI for each failure mode, then applied to the data collected from different sources, which ended with prioritizing failure modes and suggesting the best maintenance plan.

\subsection{Analysis of the collected data}

The detailed examination of the components of RP WWTP resulted in defining the failure modes of the RP WWTP, Table 14 illustrates the mechanical, electrical, and construction failure modes specified according to the reviewed documents, site visit and direct interviews, in addition to the information collected from the plant's data, and the operation and maintenance manuals. Then, the questionnaire was designed based on these failure modes and sent to 44 experts with different specializations and years of experience to their opinions. As seen in Fig. 6, the dominant type of failure mode is the mechanical type (72\% of the total number of the failure modes), next comes the electrical type failure mode $17 \%$, at last, comes the construction type failure mode $11 \%$. Despite the balance of years of experience between experts the major classes is $20-30$ year and $10-20$ which occupies $34 \%$ and $30 \%$ respectively, but concerning the specialization, $47 \%$ of the experts belong to the civil engineering, and this is a weak point in managing and implementing the maintenance activities within RP WWTP, while the most important specializations in these positions are mechanical and electrical engineering Because mechanical and electrical failure modes represent a danger to the continued operation of the station while the construction failure modes need little maintenance. In addition, Baghdad Governorate occupied the largest number of experts (65\% of the experts), due to the presence of the RP WWTP station there, which is the biggest WWTPs in Iraq.

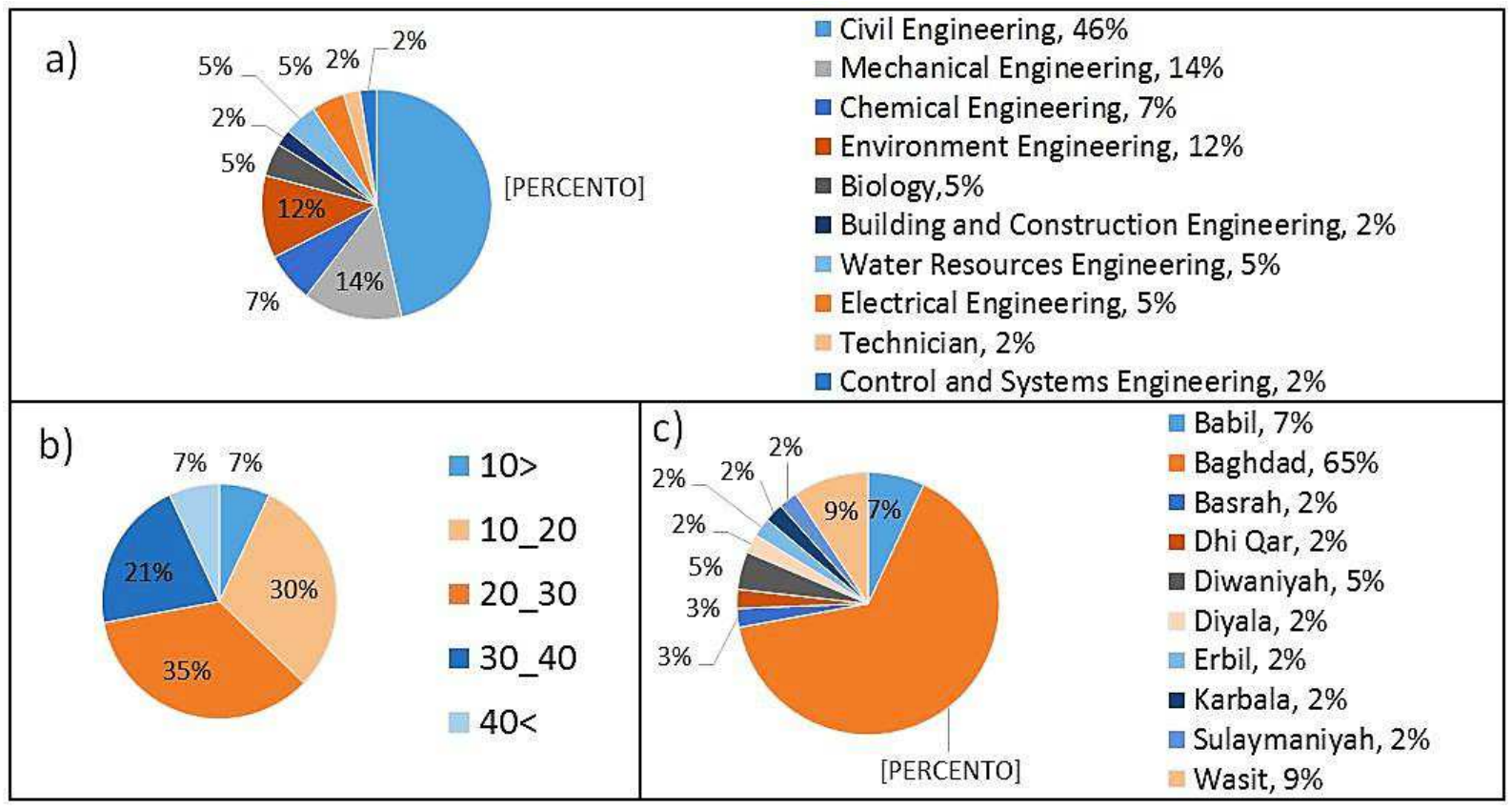

Fig. 6: Experts' information: a) specializations, b) years of experience, c) work location. 
Table 14: Failure modes of WWTP components.

\begin{tabular}{|c|c|c|}
\hline Failure modes & Failure type & Symbols \\
\hline Submersible pump & Mechanical & F-SP \\
\hline Gearbox & Mechanical & F-GB \\
\hline Valve actuator & Electrical & F-VA \\
\hline Pumps & Mechanical & F-P \\
\hline Motor & Electrical & F-M \\
\hline Condenser & Mechanical & F-C \\
\hline Electrical control board & Electrical & F-ECB \\
\hline Scrapers comb & Mechanical & F-SC \\
\hline Fan units & Mechanical & F-FU \\
\hline Valves & Mechanical & F-V \\
\hline Drums and high lines & Construction & F-DH \\
\hline Injector & Mechanical & F-I \\
\hline Rotary impeller & Mechanical & F-RI \\
\hline Conveyor belt & Mechanical & F-CB \\
\hline Conversion devices & Mechanical & F-CD \\
\hline Screen comb & Mechanical & F-CM \\
\hline Control gate & Mechanical & F-CG \\
\hline Building & Construction & F-B \\
\hline
\end{tabular}

\subsection{Failure modes risk priority index (FMRPI)}

Applying the F-FM-EA is started by computing the FMRPI. The sequential steps of computing the FMRPI with samples of the adopted data and the obtained results is shown in Tables $15-18$.

Every component within the WWTP is evaluated by the experts. Table 15 shows a random sample of the rating values for each failure mode. However, some of the data and its calculations were not presented due to the limitation of paper size. The significance Wi of the expert's opinion, which is calculated according to the experience and knowledge of experts, ranges from 0.5 to $4 \%$ in the experts' group.

In the fuzzification process, the values in Table 15 were converted to Fuzzy Triangular Numbers FTNs using Tables 2 - 5 and Eqs. 4 - 6, followed by the step of summing the FTNS for each failure mode by the application of Eqs. 7 - 10 to obtain the FTN for each indicator De, Oc and Co from F-FMEA model, see Table 16.

The process of calculating the FMRPI was based on Eq. 14, which was done after the defuzzification of the values of De, Oc, and Co in Table 16, using Eqs. $11-13$, as shown in Table 17.

The last step, which is the main reason for using FMRPI, is the ranking, which is shown in Table 18, based on the highest FMRPI for the failure modes within the RP WWTP. By looking at Table 18, it can be noticed that the submersible pump (F-SP) failure mode has the highest FMRPI, which puts it in the highest priority and gets the first rank (rank 1). However, building (F-B) failure mode takes the last rank of failure modes (rank 18), which represents the lowest priority for maintenance of all failure modes studied in this paper.

Table 15: Experts' ratings for failure modes of the Old Rustumiya WWTP (Sample).

\begin{tabular}{|c|c|c|c|c|c|c|c|c|c|c|c|}
\hline \multirow{3}{*}{ Failure mode } & \multirow{2}{*}{\multicolumn{2}{|c|}{ Expert }} & \multicolumn{9}{|c|}{ Fuzzy risk priority index } \\
\hline & & & \multicolumn{2}{|c|}{ Detection } & \multicolumn{3}{|c|}{ Occurrence } & \multicolumn{4}{|c|}{ Consequences } \\
\hline & No. & Wi & $D e 1$ & $D e 2$ & Oc1 & Oc2 & Oc3 & Co1 & Co2 & Co3 & Co4 \\
\hline \multirow{2}{*}{ F-SP } & 1 & 2 & $\mathrm{R}$ & $M$ & $\mathrm{~L}$ & $\mathrm{~L}$ & $\mathrm{VH}$ & $\mathrm{R}$ & $\mathrm{H}$ & $M$ & $\mathrm{~L}$ \\
\hline & 2 & 3 & $\mathrm{H}$ & $R$ & $\mathrm{VH}$ & $\mathrm{H}$ & $\mathrm{VH}$ & $\mathrm{VH}$ & $\mathrm{VH}$ & $\mathrm{VH}$ & $\mathrm{VH}$ \\
\hline \multirow{2}{*}{ F-VA } & 1 & 4 & $\mathrm{H}$ & $\mathrm{H}$ & $\mathrm{M}$ & $\mathrm{M}$ & $\mathrm{H}$ & $\mathrm{R}$ & $\mathrm{VH}$ & $\mathrm{M}$ & $\mathrm{R}$ \\
\hline & 2 & 1 & $\mathrm{VH}$ & $\mathrm{R}$ & $\mathrm{H}$ & $\mathrm{VH}$ & $\mathrm{H}$ & $\mathrm{H}$ & $\mathrm{H}$ & $\mathrm{H}$ & $\mathrm{R}$ \\
\hline \multirow{2}{*}{ F-FU } & 1 & 2 & $A C$ & $\mathrm{M}$ & M & M & $\mathrm{H}$ & $M$ & M & $\mathrm{H}$ & $\mathrm{M}$ \\
\hline & 2 & 4 & $\mathrm{H}$ & M & $\mathrm{H}$ & $M$ & $\mathrm{H}$ & $\mathrm{L}$ & $M$ & $\mathrm{~L}$ & $\mathrm{~L}$ \\
\hline
\end{tabular}




\begin{tabular}{|c|c|c|c|c|c|c|c|c|c|c|c|}
\hline \multirow{2}{*}{ F-V } & 1 & 0.5 & $\mathrm{VH}$ & $M$ & $M$ & $\mathrm{~L}$ & $\mathrm{H}$ & $M$ & $\mathrm{M}$ & $\mathrm{H}$ & $M$ \\
\hline & 2 & 1 & $\mathrm{VH}$ & $M$ & $\mathrm{~L}$ & $\mathrm{~L}$ & $M$ & $\mathrm{H}$ & $\mathrm{R}$ & $\mathrm{VH}$ & $\mathrm{R}$ \\
\hline \multirow{2}{*}{ F-P } & 1 & 4 & $\mathrm{VH}$ & $M$ & $M$ & $\mathrm{~L}$ & $\mathrm{H}$ & $M$ & $M$ & $\mathrm{H}$ & $M$ \\
\hline & 2 & 2 & $\mathrm{VL}$ & $\mathrm{R}$ & $\mathrm{VH}$ & $\mathrm{VH}$ & $\mathrm{H}$ & $\mathrm{H}$ & $\mathrm{H}$ & $\mathrm{H}$ & $M$ \\
\hline \multirow{2}{*}{ F-M } & 1 & 3 & $\mathrm{VH}$ & $\mathrm{R}$ & $\mathrm{VH}$ & $\mathrm{VH}$ & $\mathrm{H}$ & $M$ & $\mathrm{H}$ & $\mathrm{H}$ & $\mathrm{H}$ \\
\hline & 2 & 3 & $\mathrm{VH}$ & $M$ & $M$ & $\mathrm{~L}$ & $\mathrm{H}$ & $M$ & $M$ & $\mathrm{H}$ & $M$ \\
\hline \multirow{2}{*}{ F-ECB } & 1 & 1 & $\mathrm{VH}$ & $\mathrm{R}$ & $\mathrm{VH}$ & $\mathrm{VH}$ & $\mathrm{VH}$ & $\mathrm{H}$ & $\mathrm{VH}$ & $\mathrm{VH}$ & $\mathrm{H}$ \\
\hline & 2 & 2 & $\mathrm{~L}$ & $\mathrm{~L}$ & $\mathrm{R}$ & $\mathrm{R}$ & $\mathrm{H}$ & $\mathrm{VH}$ & $\mathrm{VH}$ & $M$ & $\mathrm{~L}$ \\
\hline \multirow{2}{*}{ F-B } & 1 & 0.5 & $\mathrm{VH}$ & $\mathrm{L}$ & $L$ & $\mathrm{R}$ & $\mathrm{L}$ & $\mathrm{R}$ & $\mathrm{L}$ & $\mathrm{H}$ & $\mathrm{H}$ \\
\hline & 2 & 2 & $A C$ & $\mathrm{H}$ & $\mathrm{R}$ & $\mathrm{R}$ & $\mathrm{R}$ & $L$ & $L$ & $\mathrm{~L}$ & $\mathrm{H}$ \\
\hline \multirow{2}{*}{ F-GB } & 1 & 3 & $\mathrm{VH}$ & $M$ & $M$ & $M$ & $\mathrm{H}$ & $M$ & $M$ & $M$ & $\mathrm{~L}$ \\
\hline & 2 & 2 & $L$ & $M$ & $M$ & $M$ & $\mathrm{H}$ & $\mathrm{L}$ & $M$ & $M$ & $M$ \\
\hline \multirow{2}{*}{ F-CG } & 1 & 4 & $\mathrm{VH}$ & $\mathrm{R}$ & $L$ & $M$ & $\mathrm{H}$ & $L$ & $L$ & $\mathrm{~L}$ & $\mathrm{~L}$ \\
\hline & 2 & 1 & $\mathrm{~L}$ & $\mathrm{~L}$ & $\mathrm{R}$ & $\mathrm{L}$ & $\mathrm{H}$ & $\mathrm{R}$ & $L$ & $\mathrm{~L}$ & $\mathrm{~L}$ \\
\hline \multirow{2}{*}{ F-CB } & 1 & 2 & $\mathrm{VH}$ & $M$ & $M$ & $\mathrm{R}$ & $\mathrm{L}$ & $\mathrm{R}$ & $\mathrm{L}$ & $\mathrm{L}$ & $\mathrm{L}$ \\
\hline & 2 & 3 & $\mathrm{~L}$ & $M$ & $\mathrm{VH}$ & $\mathrm{VH}$ & $\mathrm{H}$ & $\mathrm{H}$ & $\mathrm{H}$ & $\mathrm{H}$ & $M$ \\
\hline \multirow{2}{*}{ F-CM } & 1 & 1 & $\mathrm{VH}$ & $M$ & $L$ & $L$ & $\mathrm{H}$ & $M$ & $M$ & $M$ & $M$ \\
\hline & 2 & 3 & $\mathrm{VH}$ & $M$ & $L$ & $L$ & $\mathrm{H}$ & $M$ & $M$ & $M$ & $M$ \\
\hline \multirow{2}{*}{ F-RI } & 1 & 2 & $\mathrm{MH}$ & $\mathrm{L}$ & $\mathrm{H}$ & $M$ & $\mathrm{H}$ & $L$ & $M$ & $M$ & $\mathrm{~L}$ \\
\hline & 2 & 2 & $\mathrm{VH}$ & $M$ & $M$ & $M$ & $\mathrm{H}$ & $M$ & $M$ & $M$ & $M$ \\
\hline \multirow{2}{*}{ F-SC } & 1 & 3 & $\mathrm{VH}$ & $M$ & $M$ & $M$ & $M$ & $\mathrm{~L}$ & $\mathrm{~L}$ & $M$ & $\mathrm{~L}$ \\
\hline & 2 & 3 & $\mathrm{H}$ & $\mathrm{L}$ & $\mathrm{VH}$ & $\mathrm{H}$ & $\mathrm{H}$ & $\mathrm{H}$ & $\mathrm{H}$ & $\mathrm{H}$ & $M$ \\
\hline \multirow{2}{*}{ F-DH } & 1 & 2 & $\mathrm{H}$ & $M$ & $M$ & $M$ & $M$ & $\mathrm{~L}$ & $\mathrm{~L}$ & $M$ & $M$ \\
\hline & 2 & 3 & $\mathrm{VH}$ & $\mathrm{L}$ & $\mathrm{H}$ & $\mathrm{H}$ & $\mathrm{H}$ & $\mathrm{H}$ & $\mathrm{H}$ & $\mathrm{H}$ & $M$ \\
\hline \multirow{2}{*}{$\mathrm{F}-\mathrm{C}$} & 1 & 2 & $\mathrm{H}$ & $M$ & $\mathrm{H}$ & $\mathrm{L}$ & $M$ & $M$ & $M$ & $M$ & $\mathrm{~L}$ \\
\hline & 2 & 0.5 & $\mathrm{H}$ & $M$ & $M$ & $M$ & $\mathrm{H}$ & $M$ & $M$ & $\mathrm{H}$ & $\mathrm{L}$ \\
\hline \multirow{2}{*}{ F-I } & 1 & 3 & $\mathrm{VH}$ & $M$ & $M$ & $M$ & $\mathrm{H}$ & $\mathrm{L}$ & $M$ & $M$ & $\mathrm{~L}$ \\
\hline & 2 & 2 & $\mathrm{~L}$ & $\mathrm{~L}$ & $M$ & $M$ & $\mathrm{H}$ & $M$ & $\mathrm{~L}$ & $\mathrm{~L}$ & $\mathrm{~L}$ \\
\hline \multirow{2}{*}{ F-CD } & 1 & 2 & $\mathrm{MH}$ & $M$ & $M$ & $\mathrm{~L}$ & $\mathrm{H}$ & $\mathrm{L}$ & $\mathrm{L}$ & $M$ & $\mathrm{~L}$ \\
\hline & 2 & 3 & $\mathrm{VH}$ & $\mathrm{R}$ & $\mathrm{H}$ & $\mathrm{H}$ & $\mathrm{H}$ & $\mathrm{H}$ & $M$ & $\mathrm{H}$ & $\mathrm{H}$ \\
\hline
\end{tabular}

Table 16: Summation of failure modes sub-indicator of RP WWTP components.

\begin{tabular}{|c|c|c|c|c|c|c|c|c|c|}
\hline \multirow{2}{*}{$\begin{array}{c}\text { Failure } \\
\text { mode }\end{array}$} & \multicolumn{9}{|c|}{ Duzzy risk priority index } \\
\cline { 2 - 11 } & \multicolumn{3}{|c|}{ Detection De } & \multicolumn{3}{c|}{ Occurrence Oc } & \multicolumn{3}{c|}{ Consequences Co } \\
\cline { 2 - 11 } & Upper & Middle & Lower & Upper & Middle & Lower & Upper & Middle & Lower \\
\hline F-SP & 2.42 & 2.35 & 2.28 & 7.06 & 4.86 & 3.76 & 5.70 & 4.38 & 2.40 \\
\hline F-VA & 3.24 & 2.76 & 2.28 & 6.82 & 4.75 & 3.29 & 4.75 & 3.68 & 1.93 \\
\hline F-FU & 3.02 & 2.43 & 1.83 & 5.26 & 4.63 & 4.02 & 4.40 & 3.37 & 2.25 \\
\hline F-V & 4.75 & 3.49 & 2.23 & 6.40 & 2.85 & 0.98 & 4.88 & 3.06 & 0.92 \\
\hline F-P & 2.87 & 2.64 & 2.42 & 6.21 & 4.43 & 3.20 & 5.10 & 4.01 & 2.06 \\
\hline F-M & 3.02 & 2.76 & 2.50 & 6.34 & 4.07 & 2.73 & 4.62 & 4.04 & 2.12 \\
\hline F-ECB & 2.55 & 2.50 & 2.45 & 5.92 & 3.59 & 2.25 & 5.19 & 4.68 & 3.29 \\
\hline F-B & 3.24 & 2.20 & 1.16 & 3.88 & 1.71 & 0.41 & 5.09 & 3.74 & 2.25 \\
\hline F-GB & 2.61 & 2.58 & 2.55 & 6.74 & 5.13 & 3.55 & 4.74 & 3.71 & 2.25 \\
\hline F-CG & 2.55 & 2.19 & 1.83 & 6.68 & 4.04 & 2.06 & 3.92 & 3.11 & 1.59 \\
\hline F-CB & 3.02 & 2.70 & 2.38 & 5.39 & 3.99 & 2.99 & 4.01 & 3.05 & 1.78 \\
\hline F-CM & 3.02 & 2.76 & 2.49 & 5.39 & 3.83 & 2.17 & 3.84 & 2.92 & 1.11 \\
\hline F-RI & 2.07 & 2.04 & 2.00 & 6.34 & 5.04 & 3.68 & 4.66 & 3.66 & 1.78 \\
\hline F-SC & 2.47 & 2.44 & 2.42 & 6.21 & 4.76 & 3.55 & 4.35 & 3.41 & 2.25 \\
\hline F-DH & 2.89 & 2.61 & 2.33 & 6.34 & 3.83 & 2.04 & 4.35 & 3.44 & 2.06 \\
\hline F-C & 2.89 & 2.56 & 2.23 & 6.53 & 4.48 & 2.95 & 4.75 & 3.53 & 2.60 \\
\hline F-I & 2.42 & 2.38 & 2.33 & 6.34 & 4.69 & 3.55 & 3.71 & 3.12 & 2.12 \\
\hline F-CD & 2.29 & 2.17 & 2.06 & 6.68 & 4.56 & 3.07 & 4.19 & 3.27 & 1.78 \\
\hline
\end{tabular}


Table 17: Defuzzification results and the FMRPI for each failure mode of RP WWTP.

\begin{tabular}{|c|c|c|c|c|}
\hline Failure modes & Detection $\boldsymbol{D F}_{\boldsymbol{D e}}$ & Occurrence $\boldsymbol{D F}_{\boldsymbol{O c}}$ & Consequences $\boldsymbol{D}_{\boldsymbol{c o}_{\boldsymbol{o}}}$ & FMRPI \\
\hline F-SP & 2.35 & 5.23 & 4.16 & 51.11 \\
\hline F-VA & 2.76 & 4.95 & 3.45 & 47.17 \\
\hline F-FU & 2.43 & 4.64 & 3.34 & 37.64 \\
\hline F-V & 3.49 & 3.41 & 2.96 & 35.14 \\
\hline F-P & 2.64 & 4.61 & 3.72 & 45.38 \\
\hline F-M & 2.76 & 4.38 & 3.60 & 43.54 \\
\hline F-ECB & 2.50 & 3.92 & 4.39 & 42.97 \\
\hline F-B & 2.20 & 2.00 & 3.70 & 16.26 \\
\hline F-GB & 2.58 & 5.14 & 3.57 & 47.24 \\
\hline F-CG & 2.19 & 4.26 & 2.87 & 26.80 \\
\hline F-CB & 2.70 & 4.12 & 2.94 & 32.79 \\
\hline F-CM & 2.76 & 3.79 & 2.62 & 27.44 \\
\hline F-RI & 2.04 & 5.02 & 3.37 & 34.46 \\
\hline F-SC & 2.44 & 4.84 & 3.34 & 39.50 \\
\hline F-DH & 2.61 & 4.07 & 3.29 & 34.93 \\
\hline F-C & 2.56 & 4.65 & 3.63 & 43.22 \\
\hline F-I & 2.38 & 4.86 & 2.99 & 34.47 \\
\hline F-CD & 2.17 & 4.77 & 3.08 & 31.92 \\
\hline
\end{tabular}

Table 18: Maintenance priority of failure modes, based on FMRPI, of RP WWTP.

\begin{tabular}{|c|c|c|c|c|}
\hline Failure modes & Failure type & Symbols & FMRPI & Rank \\
\hline Submersible pump & Mechanical & F-SP & 51.11 & 1 \\
\hline Gearbox & Mechanical & F-GB & 47.24 & 2 \\
\hline Valve actuator & Electrical & F-VA & 47.17 & 3 \\
\hline Pumps & Mechanical & F-P & 45.38 & 4 \\
\hline Motor & Electrical & F-M & 43.54 & 5 \\
\hline Condenser & Mechanical & F-C & 43.22 & 6 \\
\hline Electrical control board & Electrical & F-ECB & 42.97 & 7 \\
\hline Scrapers comb & Mechanical & F-SC & 39.50 & 8 \\
\hline Fan units & Mechanical & F-FU & 37.64 & 9 \\
\hline Valves & Mechanical & F-V & 35.14 & 10 \\
\hline Drums and high lines & Construction & F-DH & 34.93 & 11 \\
\hline Injector & Mechanical & F-I & 34.47 & 12 \\
\hline Rotary impeller & Mechanical & F-RI & 34.46 & 13 \\
\hline Conveyor belt & Mechanical & F-CB & 32.79 & 14 \\
\hline Conversion devices & Mechanical & F-CD & 31.92 & 15 \\
\hline Screen comb & Mechanical & F-CM & 27.44 & 16 \\
\hline Control gate & Mechanical & F-CG & 26.80 & 17 \\
\hline Building & Construction & F-B & 16.26 & 18 \\
\hline
\end{tabular}

\subsection{Total intensity of maintenance requirements (FMTI)}

Computation of FMTI represents the second step of applying the F-FM-EA. A sample of data and calculation detail of this step is illustrated in Table 19, the intensities of each failure mode for the seven indicators (age, usage-related risk, utilization, number of available identical components, recalls and hazard alerts, function, and maintenance requirements) rated by the experts through the questionnaire were multiplied by the calculated weight of the expert, and thus total score represents the FMTI for each failure mode of RP WWTP was computed based on Eqs. 18 and 19, as shown in Table 19. 
The computed FMTI showed that the failure modes with the highest intensities 0.8 are the valve failure mode, which is mechanical failure, in addition to the electrical control board. However, the lowest intensities 0.1 are occupied by several failure modes varies among mechanical, electrical and construction, including the condenser, scraper comb, injector, and others as shown in Table 20.

Table 19: Calculations of the FMTI of the RP WWTP (Sample).

\begin{tabular}{|c|c|c|c|c|c|c|c|c|c|c|c|c|c|}
\hline \multirow{2}{*}{$\begin{array}{l}\text { Failure } \\
\text { mode }\end{array}$} & \multicolumn{2}{|c|}{ Expert } & \multirow{2}{*}{ Age } & \multirow{2}{*}{ URR } & \multirow{2}{*}{ Utilization } & \multirow{2}{*}{ Availability } & \multirow{2}{*}{ Recalls } & \multirow{2}{*}{ Function } & \multicolumn{5}{|c|}{ Maintenance requirements } \\
\hline & No. & $\begin{array}{c}\text { Wi } \\
{[\%]}\end{array}$ & & & & & & & Tools & Materials & Skills & M total & FMTI \\
\hline \multirow{2}{*}{ F-SP } & 1 & 2 & 70 & 10 & 90 & 30 & 60 & 90 & 2 & 2 & 2 & 8 & \multirow{2}{*}{0.56} \\
\hline & 2 & 2 & 10 & 90 & 10 & 10 & 40 & 10 & 3 & 2 & 3 & 18 & \\
\hline \multirow{2}{*}{ F-VA } & 1 & 4 & 80 & 10 & 90 & 50 & 30 & 90 & 2 & 2 & 2 & 8 & \multirow{2}{*}{0.38} \\
\hline & 2 & 3 & 20 & 70 & 10 & 20 & 40 & 10 & 2 & 1 & 2 & 4 & \\
\hline \multirow{2}{*}{ F-FU } & 1 & 3 & 80 & 40 & 80 & 70 & 20 & 80 & 1 & 1 & 1 & 1 & \multirow{2}{*}{0.41} \\
\hline & 2 & 2 & 20 & 90 & 10 & 70 & 40 & 10 & 3 & 2 & 3 & 18 & \\
\hline \multirow{2}{*}{ F-V } & 1 & 2 & 90 & 10 & 60 & 70 & 50 & 60 & 1 & 1 & 1 & 1 & \multirow{2}{*}{0.45} \\
\hline & 2 & 4 & 20 & 90 & 20 & 70 & 30 & 20 & 2 & 1 & 2 & 4 & \\
\hline \multirow{2}{*}{ F-P } & 1 & 1 & 70 & 40 & 90 & 60 & 50 & 90 & 2 & 2 & 2 & 8 & \multirow{2}{*}{0.51} \\
\hline & 2 & 3 & 10 & 70 & 10 & 20 & 20 & 10 & 2 & 2 & 3 & 12 & \\
\hline \multirow{2}{*}{ F-M } & 1 & 3 & 70 & 70 & 90 & 20 & 20 & 90 & 2 & 2 & 2 & 8 & \multirow{2}{*}{0.06} \\
\hline & 2 & 1 & 10 & 90 & 10 & 70 & 30 & 10 & 3 & 2 & 3 & 18 & \\
\hline \multirow{2}{*}{ F-ECB } & 1 & 2 & 90 & 100 & 100 & 70 & 20 & 100 & 1 & 1 & 2 & 2 & \multirow{2}{*}{0.80} \\
\hline & 2 & 2 & 20 & 70 & 10 & 30 & 80 & 10 & 3 & 2 & 3 & 18 & \\
\hline 50 & 1 & 2 & 80 & 40 & 40 & 70 & 40 & 40 & 1 & 1 & 1 & 1 & 01 \\
\hline & 2 & 4 & 30 & 40 & 50 & 80 & 20 & 50 & 1 & 1 & 2 & 2 & 0.1 \\
\hline $5 \subset D$ & 1 & 1 & 70 & 40 & 70 & 40 & 20 & 70 & 2 & 2 & 3 & 12 & ? \\
\hline 1 - Vo & 2 & 3 & 20 & 90 & 10 & 10 & 20 & 10 & 2 & 2 & 3 & 12 & $0.0<$ \\
\hline$F_{-} C G$ & 1 & 4 & 70 & 40 & 50 & 60 & 20 & 50 & 1 & 1 & 1 & 1 & 081 \\
\hline $1-v$ & 2 & 1 & 30 & 90 & 10 & 10 & 20 & 10 & 2 & 2 & 3 & 12 & 0.01 \\
\hline $\mathrm{F}_{\mathrm{CP}}$ & 1 & 3 & 70 & 40 & 60 & 70 & 20 & 60 & 1 & 1 & 1 & 1 & 700 \\
\hline D & 2 & 2 & 30 & 90 & 10 & 50 & 20 & 10 & 1 & 1 & 2 & 2 & 0.07 \\
\hline ECM & 1 & 4 & 70 & 40 & 60 & 60 & 30 & 60 & 1 & 1 & 1 & 1 & 006 \\
\hline 1 & 2 & 3 & 40 & 90 & 10 & 10 & 10 & 10 & 2 & 1 & 2 & 4 & 0.00 \\
\hline 50 & 1 & 2 & 70 & 40 & 50 & 20 & 30 & 50 & 1 & 1 & 1 & 1 & 010 \\
\hline $1-701$ & 2 & 2 & 20 & 70 & 10 & 10 & 30 & 10 & 2 & 2 & 3 & 12 & 0.10 \\
\hline $\mathrm{FSC}_{\mathrm{S}}$ & 1 & 1 & 70 & 40 & 50 & 70 & 30 & 50 & 1 & 1 & 1 & 1 & 0.11 \\
\hline $1-30$ & 2 & 2 & 20 & 90 & 10 & 20 & 50 & 10 & 2 & 1 & 2 & 4 & 0.11 \\
\hline 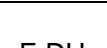 & 1 & 3 & 70 & 40 & 50 & 50 & 40 & 50 & 2 & 2 & 2 & 8 & \\
\hline г-பா & 2 & 3 & 20 & 90 & 10 & 10 & 50 & 10 & 2 & 1 & 2 & 4 & 0.00 \\
\hline EC & 1 & 2 & 60 & 40 & 40 & 70 & 40 & 40 & 2 & 2 & 2 & 8 & 010 \\
\hline$\Gamma-U$ & 2 & 4 & 10 & 90 & 20 & 50 & 20 & 20 & 2 & 2 & 3 & 12 & 0.10 \\
\hline${ }_{1}$ & 1 & 1 & 60 & 40 & 40 & 70 & 30 & 40 & 2 & 2 & 2 & 8 & $06 ?$ \\
\hline$r-1$ & 2 & 2 & 20 & 90 & 10 & 40 & 30 & 10 & 2 & 2 & 3 & 12 & 0.62 \\
\hline & 1 & 2 & 60 & 40 & 40 & 40 & 60 & 40 & 2 & 2 & 2 & 8 & $c^{2}$ \\
\hline $1--00$ & 2 & 2 & 20 & 70 & 10 & 10 & 40 & 10 & 2 & 1 & 2 & 4 & 0.00 \\
\hline
\end{tabular}

\subsection{Failure modes' maintenance plan of RP WWTP}

For suggesting the best maintenance plan of the failure modes, the computed FMRPI and FMTI, shown in Tables 18 and 19 respectively, were applied to FMRPI-FMTI diagram, Fig. 5 to obtain 
the failure modes' maintenance plan of RP WWTP, see Fig. 7, which illustrates the position of each failure mode within the diagram and the required maintenance policy was determined.

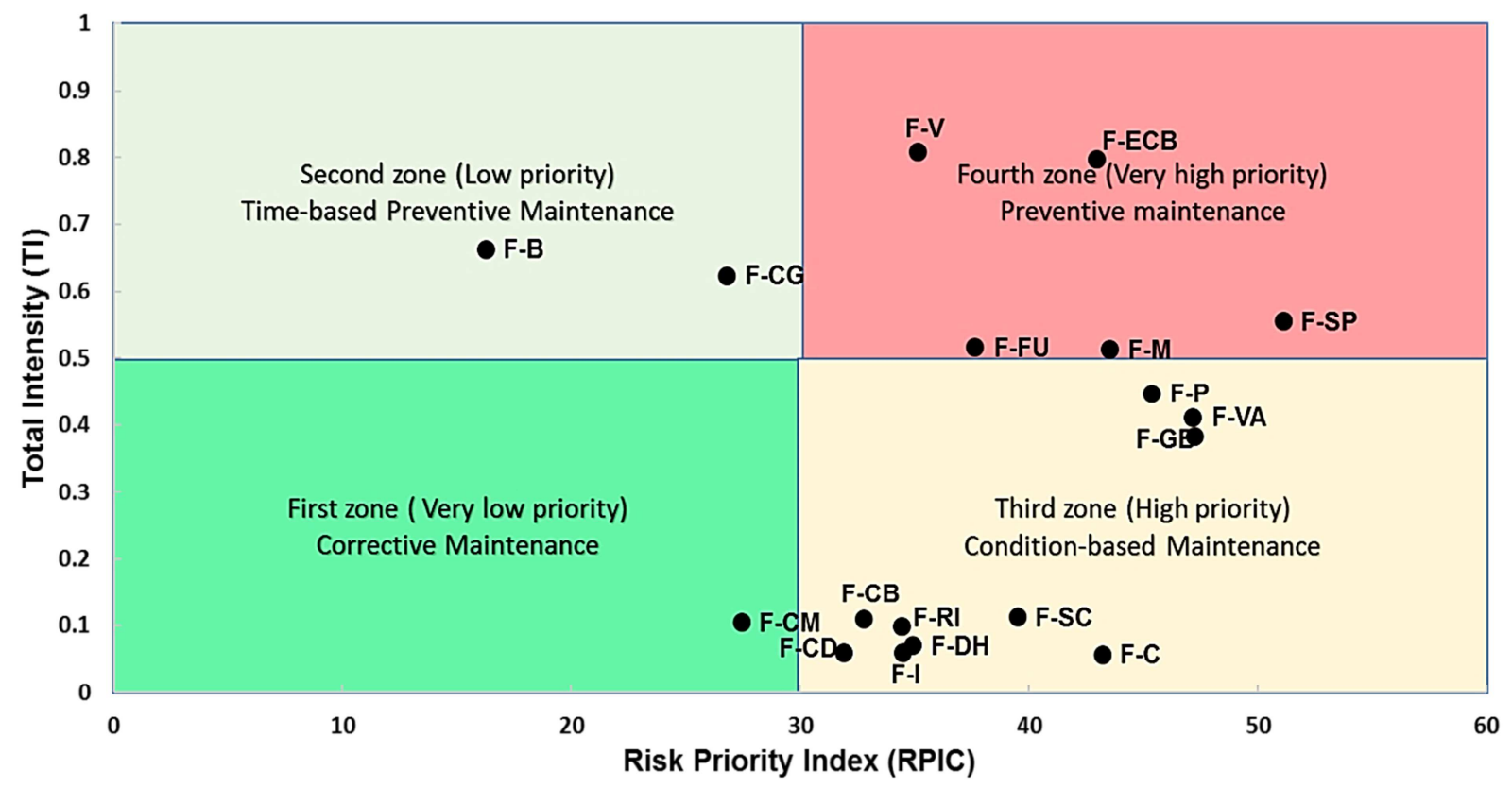

Fig. 7: FMRPI-FMTI diagram (maintenance management diagram).

The FMRPI-FMTI diagram, Fig. 7, shows that the very high priority quarter, which represents the preventive maintenance policy, includes the F-SP (Submersible Pump-Mechanical), F-M (Motor Electrical), F-ECB (Electrical Control Board - Electrical), F-FU (Fan units - Mechanical), and F-V (Valves - Mechanical) failure modes. However, the high priority quarter, which represents the Condition-Based maintenance policy, comprises most types of failure modes, including F-GB (Gearbox - Mechanical), F-VA (Valve Actuator - Electrical), F-P (Pumps - Mechanical), F-C (Condenser - Mechanical), F-SC (Scrapers comb - Mechanical), F-DH (Drums and high lines Construction), F-I (Injector - Mechanical), F-RI (Rotary impeller - Mechanical), F-CB (Conveyor belt Mechanical), and F-CD (Conversion devices - Mechanical). By descending in priority, the low priority quarter that represents the time-Based Preventive maintenance policy includes a small part of the failure modes such as F-CG (Control gate - Mechanical), and F-B (Building - Construction). Finally, the very low priority quarter represents corrective maintenance policy that includes only F-CM (Screen comb - Mechanical) failure mode. The previous arrangement of the failure modes is proportional to the data and information recorded through field visits to the study area, where the mechanical failure modes are of high importance. Thus, any minor malfunction in the mechanical parts leads to a partial stoppage in one of the plant's components. In addition, the effort and maintenance time for these failures are large and costly, followed by the electrical failure modes that may cause the suspension of one of the plant's components but requires easy maintenance and a short maintenance period. Finally, the building construction failure modes are resolved at the end of the failure mode, due to the small probability of failure also the signs of failure appear clearly and develop slowly as well as it seldom courses significant impairment to the operation of the WWTP.

\section{Conclusions}

WWTPs represent the most significant tools to control the quantities and quality of used water. To ensure its continued workability, maintenance plans must be proposed. Therefore, in this paper a fuzzy-based multi-criteria decision support system (FBMCDS) model is proposed by the means of the fuzzy logic combined with the failure mode and effect analysis (FM-EA). This model was designed and applied to specify the priority and intensity of failure modes within the WWTP and suggest the best maintenance plan for the Rustumiya WWTP. Results of applying this model indicated that the mechanical parts in the WWTP require a higher priority in the maintenance plan. This is because it represents an important element in the continuation of the WWTP's operation and its maintenance activities are complex, followed by electrical failures. Finally, the failure of the construction ranks last, due to its little need for maintenance. 
The FBMCDS model is one of the best tools in calculating weights and priorities of failure modes by including all the data and the elements affecting them. Also, it is a simple and cost effective tool for obtaining the priorities of maintenance activities within the WWTP. Furthermore, this tool can be used to facilitate the work of the maintenance plan for the administrative authorities and to ensure the continuous operation of the WWTP with required efficiency. The FMRPI-FMTI diagram (maintenance management diagram), represents an easy and sufficient technique to specify the importance of maintenance activities and the type of maintenance required without referring to the calculations and detailed data. Moreover, the final results are compatible with what was found in the obtained data, experts' opinions, the visits to the WWTP and interviews with the project administration of the Rustumiya WWTP. Using such technology in maintenance management ensures the efficient distribution of financial and human resources to the maintenance activities, thus ensuring the operation continuity of the project in accordance with the design requirements.

\section{References}

[1] ABDOLLAHI, A. A. - BABAZADEH, H. - YARGHOLI, B. - TAGHAVI, L.: Zoning the Rate of Pollution in Domestic River Using Spatial Multi-Criteria Evaluation Model. Civil and Environmental Engineering, Vol. 16, Iss. 1, 2020, pp. 49-62, doi: 10.2478/cee-2020-0006.

[2] MAHMOUD, M. A. - ALKINDI, L.: Applying Fuzzy Multi-Criteria Decision Making and Different Techniques to Solve Multi Objective Project Planning. Engineering and Technology Journal, Vol. 36, Iss. 5, 2018, pp. 533-545.

[3] AKCAN, S. - GÜLDEŞ, M.: Integrated Multicriteria Decision-Making Methods to Solve Supplier Selection Problem: A Case Study in a Hospital. Journal of Healthcare Engineering, Vol. 2019, 2019, doi: 10.1155/2019/5614892.

[4] KAHRAMAN, C. - CEBECI, U. - ULUKAN, Z.: Multi-criteria supplier selection using fuzzy AHP. Logistics Information Management, Vol. 16, Iss. 6, 2003, pp. 382-394, doi: 10.1108/ 09576050310503367.

[5] AZIZ, N. F. - SOROOSHIAN, S. - MAHMUD, F: MCDM-AHP method in decision makings. ARPN Journal of Engineering and Applied Sciences, Vol. 11, Iss. 11, 2016, pp. 7217-7220, doi: 10.1109/ TIE.2013.2297315.

[6] TONEKABONI, S. M. S. - SHAHROUDI, K.: Application of Topsis Method to Supplier Selection in Iran Auto Supply Chain. Journal of Global Strategic Management, Vol. 2, Iss. 6, 2012, pp. 123-123, doi: 10.20460/jgsm.2012615779.

[7] AAN, M. - RAHIM, R. - TINGGI, S. - MANAJEMEN, I.: Technical Approach of TOPSIS in Decision Making. International Journal of Recent Trends in Engineering and Research, Vol. 3, Iss. 8, 2017, pp. 58-64, doi: 10.23883/ijter.2017.3388.wpyuj.

[8] FU, C. - ZHENG, J. - ZHAO, J. - XU, W.: Application of grey relational analysis for corrosion failure of oil tubes. Corrosion Science, Vol. 43, Iss. 5, 2001, pp. 881-889, doi: 10.1016/S0010-938X (00)00089-5.

[9] KUNG, C. Y. - WEN, K. L.: Applying Grey Relational Analysis and Grey Decision-Making to evaluate the relationship between company attributes and its financial performance-A case study of venture capital enterprises in Taiwan. Decision Support Systems, Vol. 43, Iss. 3, 2007, pp. $842-$ 852, doi: 10.1016/j.dss.2006.12.012.

[10] SALA, A. - ALBERTOS, P.: Fuzzy Logic Controllers: Advantages and Drawbacks. Anales, Vol. III, Iss. February, 2016, pp. 833-844, doi: 10.13140/RG.2.1.2512.6164.

[11] AZADEGAN, A. - POROBIC, L. - GHAZINOORY, S. - SAMOUEI, P. - KHEIRKHAH, A. S.: Fuzzy logic in manufacturing: A review of literature and a specialized application. International Journal of Production Economics, Vol. 132, Iss. 2, 2011, pp. 258-270, doi: 10.1016/j.ijpe.2011.04.018.

[12] NHIVEKAR, G. - NIRMALE, S. - MUDHOLKER, R.: Implementation of fuzzy logic control algorithm in embedded microcomputers for dedicated application. International Journal of Engineering, Science and Technology, Vol. 3, Iss. 4, 2011, pp. 276-283, doi: 10.4314/ ijest.v3i4.68559.

[13] AL-KHAFAJI, M. S. - MESHEB, K. S. - ABRAHIM, M. A. J.: Fuzzy Multicriteria Decision-Making Model for Maintenance Management of Irrigation Projects. Journal of Irrigation and Drainage Engineering, Vol. 145, Iss. 12, 2019, pp. 04019026, doi: 10.1061/(asce)ir. 1943-4774.0001429.

[14] JONG, C. H. - TAY, K. M. - LIM, C. P.: Application of the fuzzy Failure Mode and Effect Analysis methodology to edible bird nest processing. Computers and Electronics in Agriculture, Vol. 96, 2013, pp. 90-108, doi: 10.1016/j.compag.2013.04.015. 
[15] JOSHI, G. - JOSHI, H.: FMEA and Alternatives v/s Enhanced Risk Assessment Mechanism. International Journal of Computer Applications, Vol. 93, Iss. 14, 2014, pp. 33-37, doi: 10.5120/ 16284-6047.

[16] KIM, K. O. - ZUO, M. J.: General model for the risk priority number in failure mode and effects analysis. Reliability Engineering and System Safety, Vol. 169, 2018, pp. 321-329, doi: 10.1016/ j.ress.2017.09.010.

[17] JAMSHIDI, D. A. A. - RAHIMI, S. A. - RUIZ, A.: A comprehensive fuzzy risk based framework for replacement of medical devices. 11e CONGRÈS INTERNATIONAL DE GÉNIE INDUSTRIEL, Vol. CIGI2015, 2015.

[18] ZADEH, L. A.: Is there a need for fuzzy logic? Information Sciences, Vol. 178, Iss. 13, 2008, pp. 2751-2779, doi: 10.1016/j.ins.2008.02.012.

[19] DOTE, Y.: Introduction to fuzzy logic. IECON Proceedings (Industrial Electronics Conference), Vol. 1, Iss. January, 1995, pp. 50-56, doi: 10.2298/fuee0502319m.

[20] JENSEN, F. - MORRIS, A. S. - LEVIN, M. A. - KALAL, T. T. - PASCOE, N. - CARLSON, C.: Effective FMEAs.

[21] BRAGLIA, M.: MAFMA: Multi-attribute failure mode analysis. International Journal of Quality and Reliability Management, Vol. 17, Iss. 9, 2000, pp. 1017-1033, doi: 10.1108/ 02656710010353885.

[22] TAGHIPOUR, S. - BANJEVIC, D. - JARDINE, A. K. S.: Prioritization of medical equipment for maintenance decisions. Journal of the Operational Research Society, Vol. 62, Iss. 9, 2011, pp. 1666-1687, doi: 10.1057/jors.2010.106.

[23] LI, L. - MA, L. - GONG, Y. Y. - WANG, N. C.: Study on MP-FMEA method for aviation materiel. 2011 IEEE 18th International Conference on Industrial Engineering and Engineering Management, IE and EM 2011, Iss. PART 2, 2011, pp. 1163-1168, doi: 10.1109/IEEM.2011. 6035363

[24] WANG, Y. - CHENG, G. - HU, H. - WU, W.: Development of a risk-based maintenance strategy using FMEA for a continuous catalytic reforming plant. Journal of Loss Prevention in the Process Industries, Vol. 25, Iss. 6, 2012, pp. 958-965, doi: 10.1016/j.jp.2012.05.009. 